\title{
Kibas Rumbai
}

Oleh : Nabila Triyani

(Pembimbing Tugas Akhir : Dindin Heryadi, M.Sn dan Dra. B. Sri Hanjati, M.Sn)

\author{
Jurusan Tari, Fakultas Seni Pertunjukan, Institut Seni \\ Indonesia Yogyakarta
}

Email: nbila927@gmail.com

\begin{abstract}
Ringkasan
Kibas Rumbai merupakan karya tari yang terinspirasi dari gerak kibas dan efek rumbai pada kostum. Kibas adalah gerakan yang dilakukan dengan mengayun-ayunkan beberapa anggota tubuh seperti kepala, badan, tangan, dan kaki yang digerakkan secara bergantian tetapi tidak dilakukan berurutan. sedangkan Rumbai ialah kostum yang pada tarian aslinya terbuat dari daun pisang yang dipotong kurang lebih dua atau tiga jari tangan. Pada karya ini daun yang digunakan adalah daun Gajeh. Daun gajeh memiliki tekstur yang ringan dan menghasilkan suara ketika digerakkan para penari sesuai dengan apa yang diharapakan penata.

Kibas Rumbai terisnpirasi dari tari Hudoq Kayoq pada masyarakat Dayak Bahau di Kalimantan Timur. Tari Hudoq Kayoq bertujuan meminta perlindungan Tuhan Yang Maha Esa agar tanaman padi terlindung dari serangan binatang yang dianggap sebagai hama berbahaya seperti monyet, babi, tikus, serta binatang perusak lainnya. Tari Hudoq biasanya digelar di lapangan atau sawah yang akan ditanami padi. Tari ini menggunakan ritme musik yang cepat dengan gerakan Nyidok dan Ngedok.

Pada karya tari ini, Nyidok dan Ngedok menjadi sumber dasar gerak yang akan d i gunakan sebagai langkah awal ekplorasi pe n e m u a n gerak yang akan di kembangkan dari pola ruang, waktu, dan tenaga. Karya tari ini bertipe studi yang artinya memfokuskan pada gerak berbatas dan spesifik karena tari studi menekankan pada terwujudnya sebuah kompleksitas gerak yang khas. Koreografi tari kelompok dengan jumlah penari 6 orang, dengan pembagian 3 orang penari laki-laki dan 3 orang penari perempuan.
\end{abstract}

Kata Kunci : Nyidok, Ngedok, Koreografi Kelompok 


\begin{abstract}
Kibas Rumbai is the title of this dance work. Kibas is a movement performed by a dancer by swinging a few limbs like head, body, hands, and legs are moved in turns but not done in sequence. While Rumbai is a costume that is in the original dance made of banana leaves that cut about two or three fingers of the hand. But in this work the stylist uses Gajeh leaves as a costume material that the stylist develops. The leaf has a light texture and has a voice that moves the dancers according to what the stylist is expecting.

The title of the above dance is an idea derived from the Hudoq Kayoq dance by the Dayak Bahau tribe community in East Kalimantan which is the source of the inspiration of the stylist. Hudoq Kayoq dance is aimed at asking God's protection for the One for their rice plants protected from attacks of animals that are considered as dangerous pests such as monkeys, pigs, rodents and other destructive animals. Hudoq dance is usually held in the field or rice fields that will be planted with rice. This dance uses a fairly high musical rhythm with the dancers Hudoq Nyidok and Ngedok movement.
\end{abstract}

In this dance work, Nyidok and Ngedok become the basic source of motion that will be the stylists use as the first step exploration to find the movement which is then developed through space, time, and energy. This dance work is a type of study which means focusing on motion boundaries and specific because dance studies emphasize the realization of a distinctive complexity of motion. Dancers in this work, the stylist uses 3 male dancers and 3 female dancers with a total of 6 dancers in the form of group choreography

Keywords : Nyidok, Ngedok, Studies, Choreography Group 


\section{PENDAHULUAN}

Kibas dalam Kamus Besar Bahasa Indonesia berarti gerakan seperti mengibas, sedangkan Rumbai yaitu benda yang berjuntai sama panjang dan diikat diujungnya. Pada karya ini Kibas adalah gerakan mengayun-ayunkan anggota tubuh seperti tangan, kaki, badan, dan kepala, sedangkan Rumbai merupakan kostum dari tari ini. Pada tarian aslinya kostum terbuat dari daun pisang, akan tetapi pada karya ini penata melakukan pengembangan kostum yang sudah melalui beberapa tahapan eksplorasi yaitu dengan menggunakan daun Gajeh. Daun Gajeh di sini menurut penata memiliki bahan yang ringan, mudah dibentuk, dan alasan paling utama adalah efek suara yang dihasilkan dari rumbai tersebut.

Tari Kibas Rumbai terinspirasi dari tari Hudoq Kayoq yang berkembang pada masyarakat suku Dayak Bahau di Kalimantan. Tari Hudoq Kayoq ini bertujuan meminta perlindungan Tuhan Yang Maha Esa agar tanaman padi terlindung dari serangan binatang yang dianggap sebagai hama berbahaya. Tari Hudoq biasanya digelar dilapangan atau sawah yang akan ditanami padi. Pada upacara ritual tarian tersebut hanya boleh ditarikan oleh para penari laki-laki saja, sedangkan penari perempuan mengiringi di samping para penari Hudoq. Pada tari Hudoq untuk hiburan para penari perempuan diperbolehkan untuk menari dan menggunakan topeng hudog tersebut.

Pada tarian ini terdapat gerak Nyidok yaitu gerakan maju sambil menghentak kaki dengan kuat sehingga menghasilkan suara yang keras, disusul dengan gerakan Ngedok yaitu menghentakkan kaki dengan tumit diiringi gerakan tangan yang mengibas-ngibas layaknya gerakan sayap seekor burung yang sedang terbang.

Dua gerak inilah yang manjadi langkah awal ekplorasi penata dalam melakukan pengembangan pada gerak. Kostum yang digunakan menurut penata memiliki daya tarik yang membantu membuat gerak tersebut menjadi unik dan menarik pada karya Kibas Rumbai. Untuk membantu pengembangan gerak tersebut, penata melakukannya dengan melalui pengembangan dari segi ruang, waktu, dan tenaga agar karya ini dapat lebih terarah dan tertata. Karya ini bertipe studi yang artinya memfokuskan hanya pada gerak, baik itu dari gerak dasar maupun gerak yang sudah dikembangkan. Penari pada karya ini berjumlah 6 orang yang terdiri dari 3 orang penari laki-laki dan 3 orang penari perempuan.

\section{PEMBAHASAN}

A. Konsep Dasar Tari dan Konsep Garap Tari

1. Rangsang Tari 
Rangsang awal dalam karya koreografi ini adalah rangsang visual saat melihat prosesi tarian Hudoq Kayoq dalam sebuah video dan kemudian menimbulkan rangsang gagasan untuk membuat sebuah karya tari yang mengambil sumber gerak Nyidok dan Ngedok, tidak hanya gerak saja, kostum yang digunakan juga menjadi daya tarik tersendiri.

\section{Tema Tari}

Tema pada karya ini bersifat non literal dan hanya berfokus pada gerak, karena penyajian karya tari ini bersifat studi gerak Nyidok dan Nyedok yang berfokus pada pengolahan gerak kepala, badan, tangan dan kaki.

\section{Judul Tari}

Kibas adalah gerakan yang dilakukan oleh penari dengan mengayun- ayunkan beberapa anggota tubuh seperti kepala, badan, tangan, dan kaki yang digerakkan secara bergantian tetapi tidak dilakukan berurutan. Sedangkan Rumbai ialah busana dari daun Gajeh yang diikat, dipotong, dan kemudian dibentuk menjadi beberapa bagian sehingga disebut dengan rumbai yang dipasangkan pada bagian tubuh. Judul yang penata buat pada karya tari ini sangat berkaitan dengan konsep garapan dalam karya ini, yakni gerak Nyidok, Ngedok, dan busana yang menjadi sumber inspirasi pembuatan karya ini.

\section{Bentuk dan Cara Ungkap}

Nyidok dan Ngedok menjadi sumber dasar gerak yang digunakan sebagai langkah awal eksplorasi penemuan gerak kemudian dikemas dengan bermain ruang, waktu, dan tenaga. Karya tari ini bertipe studi yang artinya memfokuskan pada gerak berbatas dan spesifik karena tari studi menekankan pada terwujudnya sebuah kompleksitas gerak yang khas. Pada karya ini penata menggunakan repetisi atau pengulangan dibeberapa motif gerak. Pengulangan begitu penting dalam sebuah koreografi ini agar suatu bentuk atau motif gerak menjadi satu motif dasar yang jelas ketika dikembangkan. Ciri khas sajian sebuah koreografi, sebaiknya perlu diulang beberapa kali, dengan maksud untuk lebih menampakkan kekhasan bentuk koreografi tersebut. Pengulangan digunakan untuk memancing ingatan dan satu cara penyampaian ide tetapi juga sebagai metode untuk menyerap gerakan.

\section{Gerak}

Gerak Nyidok dan Ngedok dilakukan dengan menggunakan anggota tubuh seperti badan, tangan, dan kaki yang mendominasi pada karya tari ini, sedangkan kepala bergerak bebas menggunakan topeng yang mana gerak tersebut memberikan kesan hidup pada topeng tersebut. Saat melakukan gerak tersebut dapat dilakukan dengan cara posisi badan tegak, dengan kaki yang terangkat menyilang di atas 
kaki tumpuan sehingga badan terayun ke kiri dan ke kanan. Tangan terayun ke atas setinggi bahu, lalu dijatuhkan menepuk paha. Saat mengambil langkah, kaki dihentak kuat ke bawah (lantai) untuk menghasilkan suara yang keras. Suara hentakkan kaki disusul oleh tepukan tangan ke paha membuat busana yang berumbai tersebut berbunyi. Gerak pada kepala merupakan efek dari topeng yang digunakan, gerak yang terlihat seperti burung yang sedang melihat ke segala arah. Bentuk topeng pada tarian aslinya menggunakan bahan yang terbuat dari kayu dengan bentuk berbeda-beda menyerupai beberapa bentuk hewan yang dianggap sebagai hama perusak tanaman padi mereka. Pada karya Kibas Rumbai, bahan topeng terbuat dari sponge ati. Alasan penata menggunakan bahan tersebut karena sponge ati merupakan bahan yang ringan sehingga akan lebih aman ketika penari melakukan gerak dibandingkan jika menggunakan topeng asli yang terbuat dari kayu.

\section{Penari}

Karya tari ini dikemas ke dalam bentuk koreografi kelompok dengan 6 orang penari yang terdiri dari 3 penari laki-laki dan 3 penari perempuan. Perbedaan jenis kelamin pada tarian ini jika pada prosesi ritual atau upacara, tarian tersebut hanya bisa ditarikan oleh penari laki-laki saja, sedangkan penari perempuan hanya bisa berjajar mengelilingi para penari Hudoq. Akan tetapi, jika untuk keperluan di luar acara ritual atau upacara, perempuan boleh ikut menarikan tari Hudoq tersebut. Perbedaan jenis kelamin di karya tari ini dikarenakan untuk keperluan di luar prosesi ritual atau upacara. Mengapa penata tertarik dengan hal tersebut, karena karya tari ini bersumber dari gerak Nyidok dan Ngedok yang dikemas ke dalam studi gerak, maka menurut penata tidak ada larangannya. Jumlah penari pada tarian aslinya tidak ada ketetapan sama sekali, semakin banyak penarinya maka akan semakin bagus, dari hal inilah jumlah pada karya Kibas Rumbai tidak ada ketetapannya, penata hanya ingin lebih mengeksplor dengan menggunakan jumlah 6 penari tersebut.

\section{Musik Tari}

Tari ini terdiri dari 3 bagian, sehingga musik juga ditata dengan tiga suasana untuk membantu membedakan bagian satu, dua dan tiga agar terlihat menarik dan tidak membosankan. Pada bagian pertamamusik yang dipakai adalah vocal Dayung untuk mendukung suasana sebelum memulai ritual tari dimulai, dan kemudian sambil memasukan ilustrasi musik dengan sedikit pukulan suara kempul dan petikan sape. Bagian kedua suasana yang dibentuk adalah sedikit menegangkan, karena pada adegan ini bagianperbagian anggota tubuh masing-masing dari penari mengenakan kostum yang terbuat dari 
daun Gajeh di mana maksud dari daun gajeh tersebut merupakan salah satu pengembangan kostum. Adegan ketiga suasana musik yang digunakan lebih kepada suasana ritual, karena pada bagian ini akan menunjukkan tarian Hudoq yang menggunakan baju dari daun pisang, dengan memakai topeng yang bentuknya sudah dikembangkan.

Tarian terlihat sangat enerjik ketika semua kostum sudah dipakai seperti baju dari daun pisang yang menutup seluruh anggota tubuh, dan dengan topeng yang menutup wajah. Ketika tarian dimulai para penari menari dengan mengibas-ngibaskan tangan

yang kemudian ditepuk ke paha sehingga menimbulkan suara, dan kemudian kepala bergerak bebas dengan patah-patah seperti gerakan kepala burung.

\section{Pemanggungan}

Pada tarian aslinya, tari Hudoq Kayoq biasanya dipertunjukkan di lapangan atau sawah yang akan ditanami padi, tetapi karya ini akan dipentaskan di Proscenium Stage. Kenapa penata menggunakan Proscenium Stage karena tempat tersebut memiliki samping kiri kanan yang sangat membantu ke luar dan masuknya penari agar mengurangi kebocoran ketika ada pergantian kostum.

\section{Rias dan Busana}

Kostum dari daun Gajeh dipakai saat para penari melakukan gerak kibasan, guna menonjolkan efek kibasan rumbai tersebut. Sedangkan pada bagian ending menggunakan baju Hudoq yang terbuat dari daun pisang berwarna hijau, dengan topeng Hudoq yang sudah dikembangkan terbuat dari sponge ati. Pada bagian yang menggunakan kostum dari daun pisang tersebut dikenakan para penari laki-laki berjumlah 3 orang. Kostum yang terbuat dari daun pisang dipotong selebar kurang lebih dua sampai tiga jari tangan sehingga berbentuk rumbai, yang berguna untuk menutup seluruh anggota tubuh penari. Pada leher dipasang menjulur kain warna merah, warna yang dipercaya oleh Suku Dayak Bahau sebagai warna kesukaan para Dewa.

\section{Proses Penciptaan}

Tahapan proses penciptaan karya ini penata tertarik dengan konsep yang digunakan Hendro Martono dalam bukunya yang berjudul Koreografi Lingkungan (Revitalisasi Gaya Pemanggungan dan Gaya Penciptaan Seniman Nusantara). Pada buku tersebut dijelaskan tentangproses kreatif dengan tahapan yang

mengutamakan penemuan disain, motif dan teknik gerak, musik, serta aspek-aspek pendukung artistik. Buku ini juga menerapkan tentang sensasi ketubuhan, sensasi emosi, sensasi imaji, dan ritus ekspresi dalam menciptakan suatu proses yang kreatif. Untuk memulai proses karya ini dilakukan 
dengan bekerja melalui sebuah khayalan atau imajinasi yang membantu motivasi dari yang kurang jelas sehingga ada satu masa pencarian tersebut atau angan-angan menjadi jelas. Hal inilah yang memberikan berbagai perasaan dalam pencarian gerak yang kemudian disalurkan kepada penari untuk tahapan proses eksplorasi agar gerak yang ingin disampaikan dapat lebih jelas dan mudah dimengerti oleh para penari.

\section{B.Paparan Hasil Penciptaan}

\section{Introduction}

Pada bagian introduksi satu penari menggunakan kostum dari daun Gajeh yang dipasang pada lengan dan digenggam oleh penari tersebut dengan melakukan gerakan Nyidok dan Ngedok, dan kemudian dikembangkan melalui beberapa anggota tubuh yang membantu dalam eksplorasi sehingga menjadi garapan yang tertata.

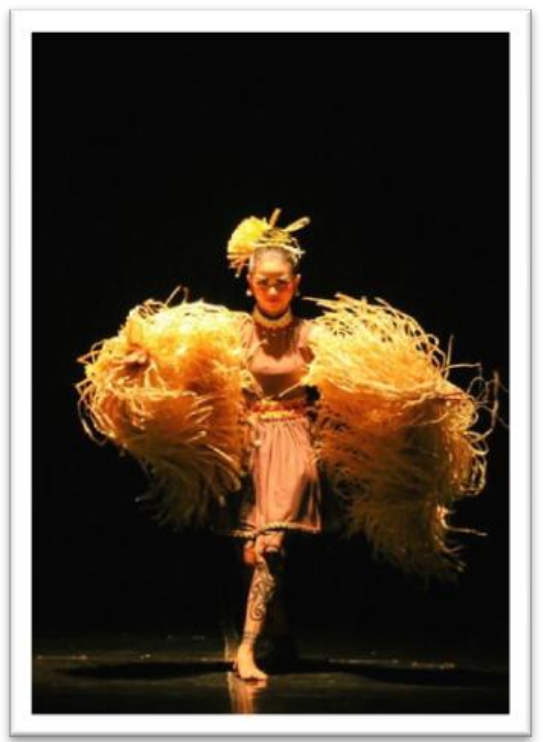

Gambar 1 : Sikap penari bagian introduksi ketika berdiri ( Foto : Maissy, 2018 )

\section{Bagian 1}

Pada bagian pertama para penari melakukan rampak gerak dari pengembangan gerak Nyidok dan Ngedok yang sudah dikembangkan dengan pengolahan ruang, waktu, dan tenaga. Suasana musik yang digunakan berangkat dari tradisi dengan pengembangan.

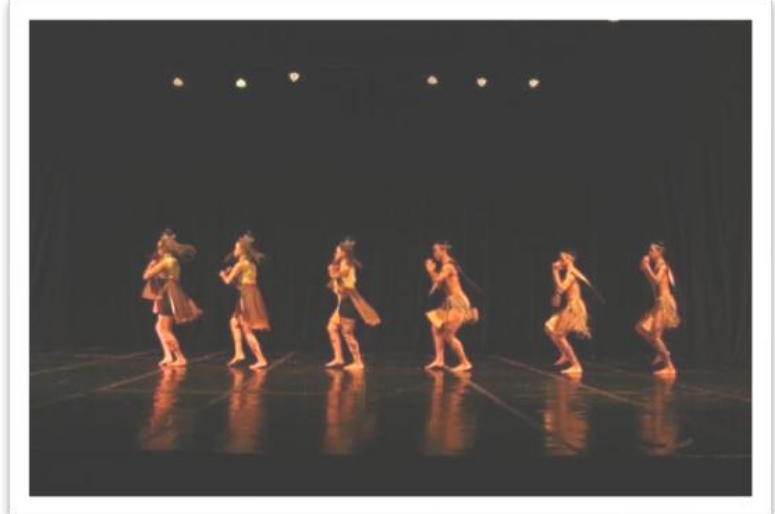

Gambar 2 : Sikap penari laki-laki menjemput penari perempuan (Foto : Maissy, 2018)

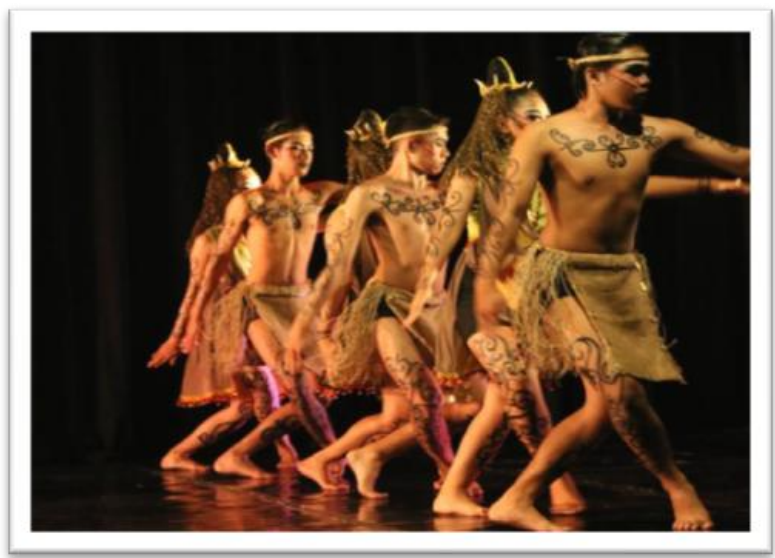

Gambar 3 : Sikap penari perempuan menjemput penari laki-laki (Foto : Maissy, 2018)

\section{Bagian 2}

Bagian kedua suasana yang sedikit menegangkan, karena pada adegan ini perbagian anggota tubuh masing-masing dari 
penari menggunakan kostum dari daun Gajeh yang dibentuk sesuai dengan anggota tubuh penari yang dibagi pada bagian lengan, badan, dan kaki.

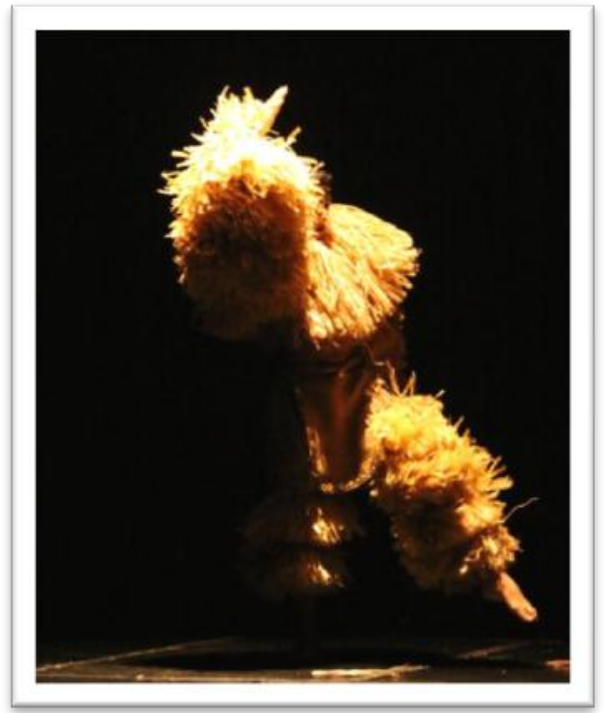

Gambar 4 : Sikap penari laki-laki menggunakan kostum rumbai (Foto : Maissy, 2018)

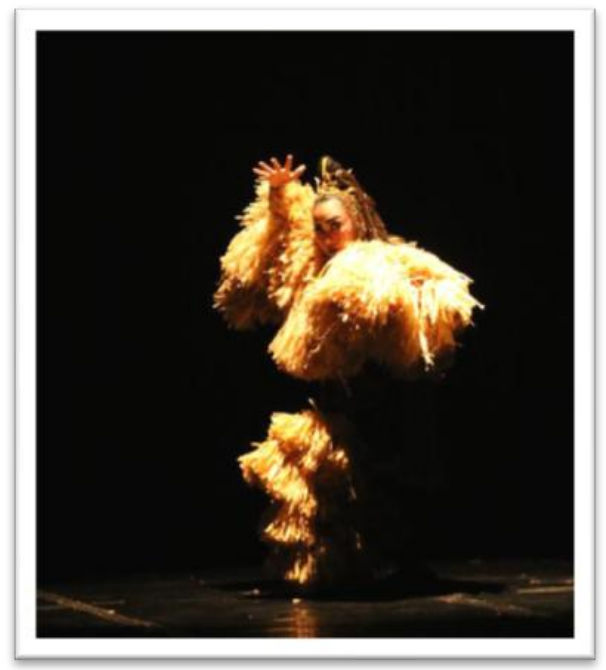

Gambar 5 : Sikap penari perempuan menggunakan kostum rumbai (Foto : Maissy, 2018)

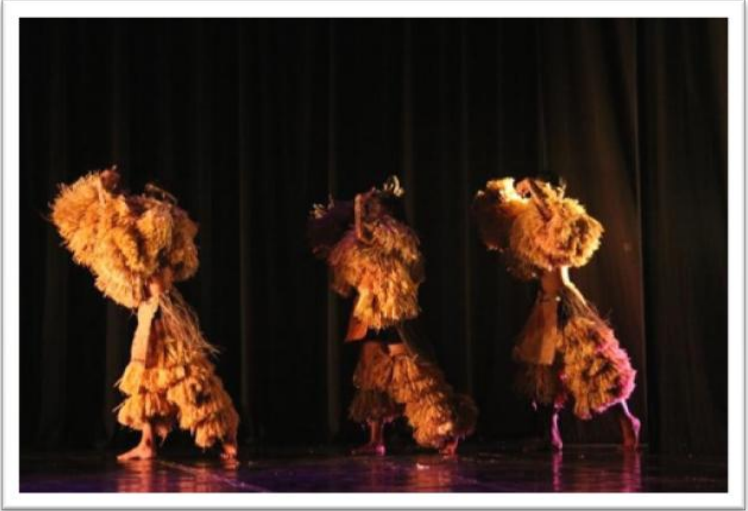

Gambar 6 : Sikap tiga penari menggunakan kostum rumbai

(Foto : Maissy, 2018)

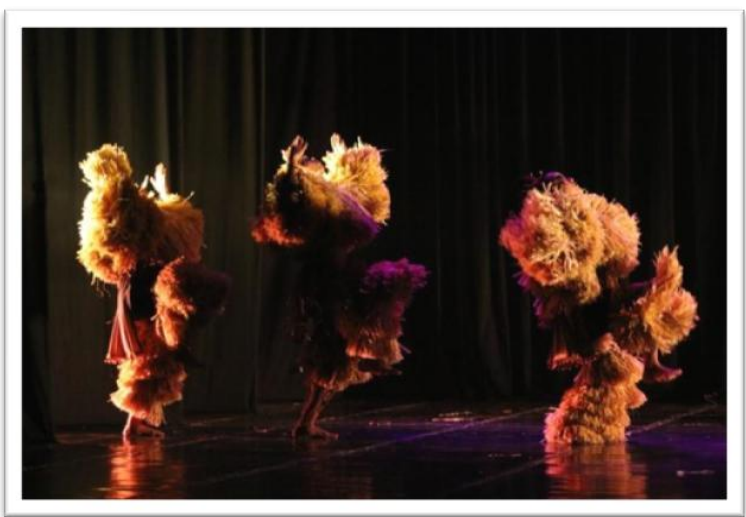

Gambar 7 : Sikap tiga penari menggunakan kostum rumbai

(Foto : Maissy, 2018)

\section{Bagian 3}

Adegan ketiga suasana yang digunakan lebih kepada suasana musik ritual, lebih fokus kepada gerak penari yang menggunakan kostum rumbai yang terbuat dari daun pisang. Pada bagian ini menunjukkan tarian sudah menggunakan kostum dari daun pisang yang menutup seluruh anggota tubuh, dan dengan topeng yang menutup wajah. Ketika tarian dimulai para penari menari dengan mengibasngibaskan tangan yang kemudian ditepuk ke 
paha sehingga menimbulkan suara, dan kemudian kepala bergerak bebas dengan patah-patah seperti gerakan kepala burung.

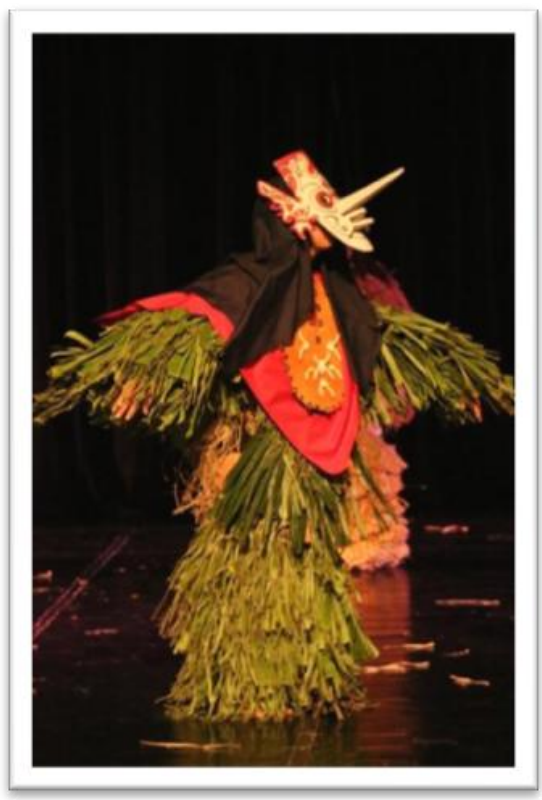

Gambar 8 : Sikap gerak penari Hudoq (Foto : Maissy, 2018)

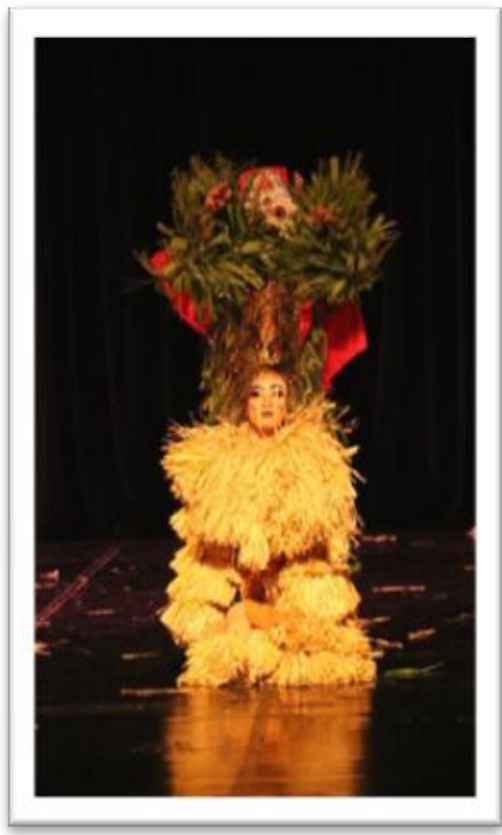

Gambar 9 : Sikap gerak penari perempuan mengibas rambut (Foto : Maissy, 2018)

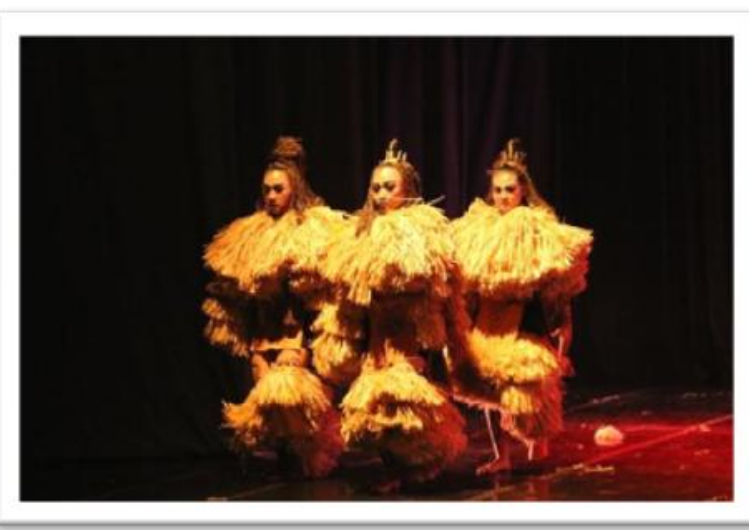

Gambar 10 : Sikap penari perempuan berjalan transisi

(Foto : Maissy, 2018)

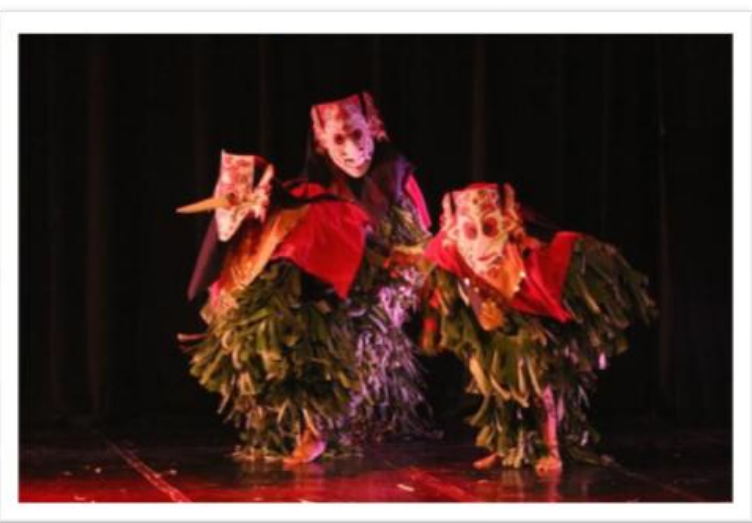

Gambar 11 : Sikap penari laki-laki menggunakan topeng Hudoq

(Foto : Maissy, 2018)

\section{PENUTUP}

Karya tari Kibas Rumbai ini merupakan ide yang berasal dari tari Hudoq Kayoq pada masyarakat suku Dayak Bahau di Kalimantan Timur yang menjadi sumber inspirasi penata. Tari Hudoq Kayoq ini bertujuan meminta perlindungan Tuhan Yang Maha Esa agar tanaman padi mereka terlindung dari serangan binatang yang 
dianggap sebagai hama berbahaya seperti monyet, babi, tikus serta binatang perusak lainnya. Pada tari Hudoq Kayoq terdapat gerak Nyidok dan Ngedok yang menjadi dasar gerak yang akan penata gunakan sebagai langkah awal ekplorasi untuk mengembangkannya yang kemudian dikreasikan dengan bermain ruang, waktu, dan tenaga. Kostum yang digunakan tarian ini sangat berpengaruh dalam bentuk penyajiannya, inilah menjadi salah satu hal yang menjadi perhatian penata untuk membuat sebuah karya Kibas Rumbai.

$$
\text { Penata tertarik membuat }
$$

sebuah karya tari dengan mengambil gerak Nyidok dan Ngedok sebagai sumber inspirasi dalam karya tari Kibas Rumbai. Pada karya tari ini piñata mencoba bereksplorasi untuk menemukan pengembangan dari gerak Nyidok dan Ngedok tersebut. Pengarapan karya tari ini busana yang digunakan menjadi sumber pencarian gerak yang dimana ketika busana tersebut digerakkan dengan menggunakan gerak Nyidok dan Ngedok dapat menimbulkan suara dari efek kibasan tersebut.

\section{DAFTAR SUMBER ACUAN}

\section{A. Sumber Tercetak}

Hadi, Y. Sumandiyo. 2012. Seni Pertunjukan dan Masyarakat Penonton.

Yogyakarta: BP ISI Yogyakarta.

\section{Koreografi}

Bentuk-Teknik-Isi. Yogyakarta: Cipta Media Yogyakarta.

Haryanto, 2015. Musik Suku Dayak Sebuah Catatan Perjalanan di Pedalaman

Kalimantan. Yogyakarta: Institut Seni Indonesia Yogyakarta.

Hawkins, Alma M. 1990. Creating Through Dance. Terjemahan oleh Y. Sumandiyo Hadi dengan judul Mencipta Lewat Tari. Yogyakarta: ISI Yogyakarta.

Mack, Dieter. 2001. Musik Kontemporer dan Persoalan Interkultural. ARTI.

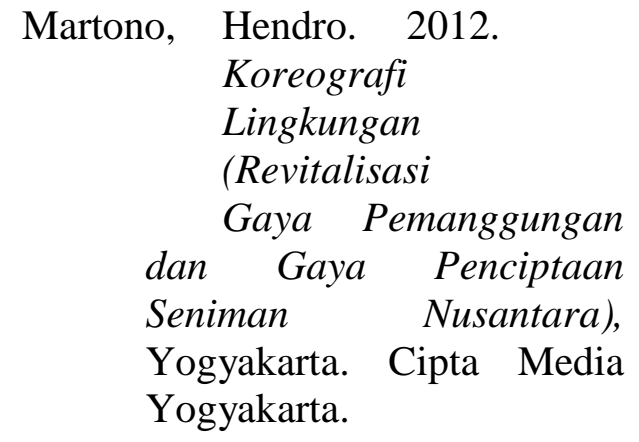

Maunati, Yekti. 2004. Identitas Dayak Komodifikasi \& Politik Kebudayaan. Yogyakarta: LkiS Yogyakarta.

Nuraini, Indah. 2011. Tata Rias \& Busana Wayang Orang Gaya Surakarta,

Yogyakarta. ISI Yogyakarta.

Sachari, Agus. 2002. Estetika

(Makna, Simbol dan

Daya), Bandung. ITB 
Bandung.

Smith, Jacqueline. 1976. Dance Composition Pratical Guide For Teacher, London. Lepus Books. Terjemahan Ben Suharto, Komposisi Tari Sebuah Petunjuk Praktis Bagi Guru, 1985.

\section{B. Narasumber}

Gregorius Milang, 17 tahun, penari dan sekaligus suku Dayak Bahau.

Octavia Idang, 20 tahun, masyarakat suku Dayak Bahau.

Yosintha Gering Lawing, 22 tahun, masyarakat.

\section{Webtografi}

https://www.youtube.com/watch? $v=i E 9 Q \mathrm{Q}$ r9Wygc

https://www.voutube.com/watch?v=bRu5W8

\section{$\underline{\operatorname{TR} 919}$}

https://www.voutube.com/watch? $v=I P D p b p$

\section{N6ZII}

